\title{
Molecular Study of a Hoxa2 Gain-of-Function in Chondrogenesis: A Model of Idiopathic Proportionate Short Stature
}

\author{
Pierre M. L. Deprez ${ }^{1}$, Miloud G. Nichane ${ }^{2}$, Benoît G. Lengelé ${ }^{3}$, René Rezsöhazy $^{2}$ and
} Catherine Nyssen-Behets ${ }^{3, *}$

1 Ecole de Kinésiologie et Récréologie, Faculté des Sciences de la Santé et Services Communautaires, Université de Moncton, Moncton, NB E1A 3E9, Canada; E-Mail: pierre.deprez@umoncton.ca

2 Embryologie Moléculaire et Cellulaire Animale, Institut des Sciences de la Vie, Université catholique de Louvain, Louvain-la-Neuve 1348, Belgium;

E-Mails: miloud.nichane@uclouvain.be (M.G.N.); rene.rezsohazy@uclouvain.be (R.R.)

3 Pôle de Morphologie, Institut de Recherche Expérimentale et Clinique,

Université catholique de Louvain, Brussels 1200, Belgium; E-Mail: benoit.lengele@uclouvain.be

* Author to whom correspondence should be addressed; E-Mail: catherine.behets@uclouvain.be; Tel.: +32-2-764-5245; Fax: +32-2-764-5225.

Received: 13 June 2013; in revised form: 16 September 2013 / Accepted: 16 September 2013 / Published: 14 October 2013

\begin{abstract}
In a previous study using transgenic mice ectopically expressing Hoxa 2 during chondrogenesis, we associated the animal phenotype to human idiopathic proportionate short stature. Our analysis showed that this overall size reduction was correlated with a negative influence of Hoxa2 at the first step of endochondral ossification. However, the molecular pathways leading to such phenotype are still unknown. Using protein immunodetection and histological techniques comparing transgenic mice to controls, we show here that the persistent expression of Hoxa2 in chondrogenic territories provokes a general down-regulation of the main factors controlling the differentiation cascade, such as Bapx1, Bmp7, Bmpr1a, Ihh, Msx1, Pax9, Sox6, Sox9 and Wnt5a. These data confirm the impairment of chondrogenic differentiation by Hoxa2 overexpression. They also show a selective effect of Hoxa2 on endochondral ossification processes since Gdf5 and Gdf10, and Bmp4 or PthrP were up-regulated and unmodified, respectively. Since Hoxa2 deregulation in mice induces a proportionate short stature phenotype mimicking human idiopathic conditions, our results give an insight into understanding proportionate short stature pathogenesis by highlighting molecular factors whose combined deregulation may be involved in such a disease.
\end{abstract}


Keywords: proportionate short stature; endochondral ossification; Hoxa2; chondrogenesis

\section{Introduction}

Proportionate short stature (PSS) is a growth-related disease that is characterized by a severe reduction in the length of the trunk and limbs, resulting in adult patients with smaller but proportional body parts [1]. The main causes of short stature are well known and can be classified as either primary (associated with Turner syndrome, osteogenesis imperfecta or IGF-I deficit, for example) or secondary (a consequence of malnutrition, growth hormone deficiency or irradiation, for example). However, idiopathic cases of short stature are still often reported [2].

While characterizing a Hoxa2 gain-of-function transgenic mouse model in order to study the functional relationship between Hox genes activity and the control of chondrogenic differentiation, we observed that the persistent and ectopic activity of Hoxa2 in cartilage led to a reduction of ossification centers. This reduction impacted the endochondral ossification process, resulting in a postnatal growth defect mimicking human PSS [3,4]. Indeed, whereas the transgenic mice were similar in size to the control animals at birth, they featured a significant but harmonious shortening of both the trunk and the appendicular skeleton as early as the day four. We determined that this reduced length phenotype in a mouse skeleton was not due to gross proliferation, apoptosis or endochondral ossification impairments, but was rather related to a decrease in the number of cells entering chondrogenesis [4]. The diagnostic approach for short stature [2] helped associate this mouse phenotype to idiopathic PSS.

Skeletogenesis is a developmental process consisting of two main differentiation pathways in which undifferentiated mesenchymal cells first differentiate into osteoblasts or chondrocytes to later enter osteogenesis or chondrogenesis, respectively. While the former implies direct formation of bone and involves multiple maturation steps leading the osteoblast to become a mature osteocyte $[5,6]$, the latter leads the chondrocyte to proliferate, to hypertrophy and then, after physiological death, leave empty lacunae for osteoblast deposition through vascular invasion [7,8]. These developmental pathways are called intramembranous (or dermal) and endochondral ossification, respectively.

The molecular control of endochondral ossification is quite complex. After condensation, mesenchymal cells differentiate into chondrocytes through the induction of the major regulator of chondrogenesis, Sox9 [9]. Sox9 induction relies on Pax1 and Pax9 through Bapx1 stimulation [10]. During its first step, chondrogenesis is also stimulated by Msx1, Msx2, as well as Wnt5a, Bmp7 and Bmp4 signaling [11-14]. Afterwards, a positive regulatory feedback loop between Sox 9 and Bapx1 induces cellular proliferation [15]. Sox9 maintains chondrocyte proliferation with the help of its partners, Sox5 and Sox6. Paracrine influences support this cell multiplication process by PthrP, Ihh, Bmp7 and Bmpr1a [16,17]. Next, Sox9 is inhibited by Wnt5a through $\beta$-catenin [18]. This allows for maturation into hypertrophic chondrocytes. This maturation step is also stimulated by Bmpr1a activation as well as by Runx2, and Msx2 transcription factors [19-21]. Finally, Runx2 expression brings hypertrophic chondrocytes to physiological death and triggers osteogenesis [22]. In this regard, it has been suggested that Runx2 is inhibited by Sox9 through Bapx1 stimulation during hypertrophy [23]. 
While we previously showed in a gain-of-function transgenic mouse model that Hoxa2 may impact on the mesenchymal-to-chondrocyte differentiation step and give rise to a proportionate short stature phenotype [4], we show here that several molecular regulators of endochondral ossification are significantly decreased by a Hoxa 2 gain-of-function in chondrogenesis.

\section{Results and Discussion}

In 2007, Massip and colleagues generated a transgenic mouse model which induced Hoxa2 gene expression in a Cre-mediated way [3]. Crossing these mice with Col2a1-Cre transgenics [24] provoked an ectopic and persistent expression of Hoxa2 in every Col2al expressing cell, i.e., in all cells initiating chondrogenesis. The resulting Col2a1/Hoxa2-lacZ mice displayed cartilage defects as E18.5 embryos featured a reduction of ossification centers in their skeleton. In-depth analysis of their postnatal phenotype revealed they could be used as a suitable model for the study of the idiopathic PSS in humans considering the proportionate small body size of the animals could not be associated with syndromes, pathologies or other known disorders [4]. By analyzing the impact of Hoxa2 on chondrogenesis, we excluded any significant impairment on the proliferation rate, apoptosis, maturation rate and ultrastructure of chondrocytes. Instead, it appeared that the expression of Hoxa2 at the onset of chondrogenesis exerts an inhibitory influence on the mesenchymal-to-chondrocyte differentiation, particularly via a decreased number of cells entering differentiation [4]. These data were consistent with previous observations which showed that Hoxa2 expression is detected in every mesenchymal cell of the future cartilaginous template of the second branchial arch derivatives. However, its expression is no longer detected as soon as chondrogenesis starts, i.e., concomitant with Sox9 expression [25].

In order to understand the molecular disruption that takes place in the Hoxa2-induced short stature phenotype, embryos carrying both transgenes (Col2a1/Hoxa2-lacZ) or only the $\beta S$-Hoxa2-lacZ transgene were processed for immunohistochemistry and western blotting towards several regulators of skeletal development. Indeed, when deregulated, some of regulators induce similar phenotypical characteristics to our transgenic model (see below). For example, while Bapxl knockout mice feature an absence of ossification centers in their cervical vertebrae [26], Bmp7 null animals present a severe postnatal size reduction [27]. We compared the expression level of these factors using tissue immunostaining in the vertebrae of Col2al/Hoxa2-lacZ and $\beta S$-Hoxa2-lacZ E13.5 embryos because almost every part of the skeleton is under development at this stage (Figure 1A). After total excision, the spine of E13.5 mutants and controls was processed for western blotting and semi-quantification of western blot signals was carried out (Figure 1B).

We showed that mice with an ectopic expression of Hoxa2 feature decreased Bapx1, Bmp7, Bmpr1a, Ihh, Msx1, Pax9, Sox6, Sox9 and Wnt5a and increased Gdf5 and Gdf10 protein levels. When significant, the protein level reductions reached up to one eighth of the control ones. The other molecules showed similar patterns for both immunohistochemistry and western blots (Figure 1). This is interesting since most of the decreased proteins stimulate the mesenchymal-to-chondrocyte transition [10,11,15,28-31] (Figure 2, left panel). This is consistent with the observation that continued Hoxa 2 expression impairs the early differentiation of mesenchymal cells into chondrocytes [4]. 
Figure 1. Immunohistochemistry (A) and western blotting (B) on E13.5 $\beta S$-Hoxa2-lacZ (left) and Col2a1/Hoxa2-lacZ (right) vertebral bodies. (A) Runx2 was unmodified at E13.5 but reduced in pre- and hypertrophic chondrocytes as shown in E15.5 and E16.5 limbs, respectively; (B) Immunoblots are featured as follows (from top to bottom): the targeted molecule, $\beta$-actin as a control and the semi-quantification results using mean gray values. (a) $p<0.05$; (b) $p<0.005$ and (c) $p<0.0005$. Magnification $40 \times$. Scale bar $=0.1 \mathrm{~cm}$. $n=5$.

A
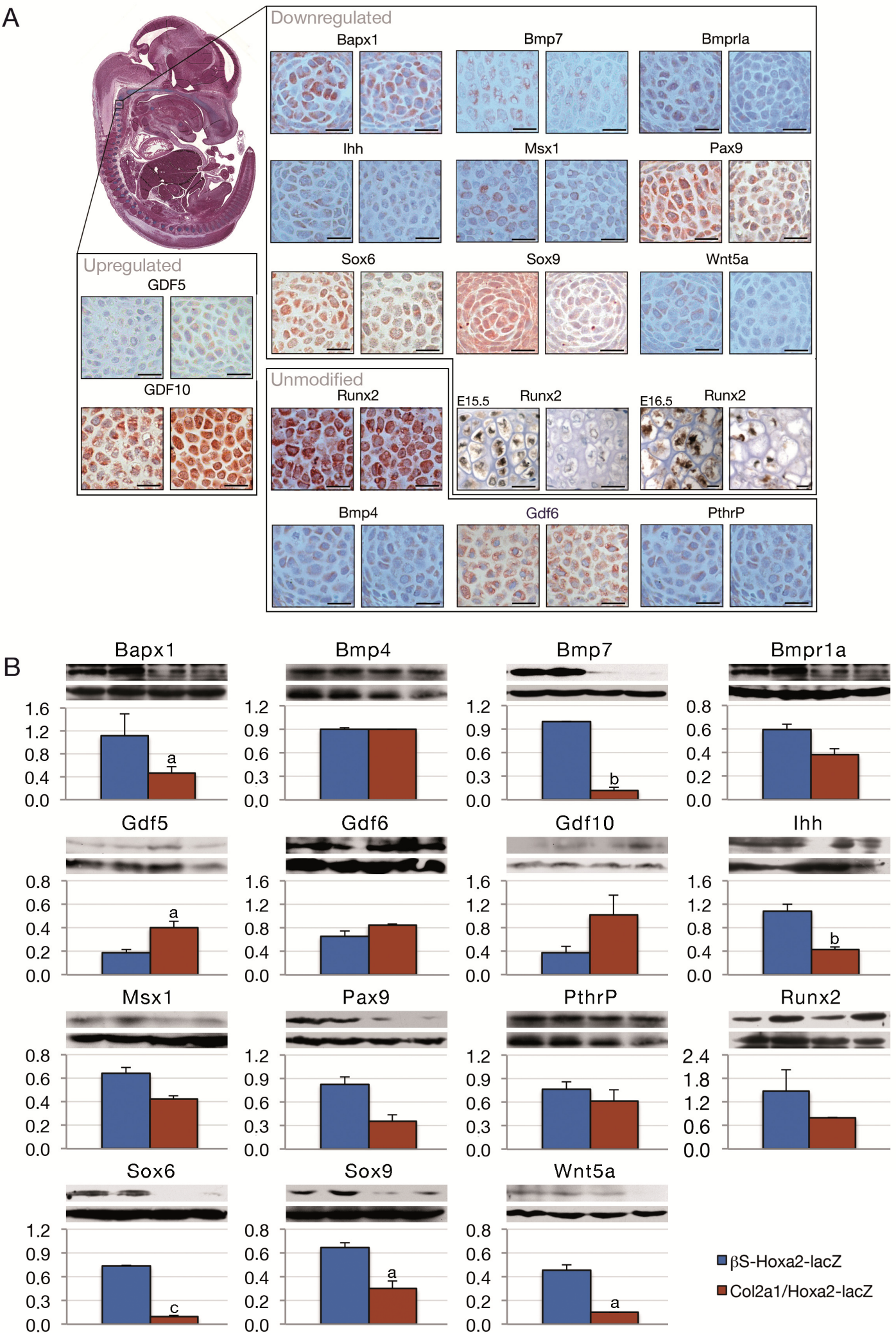

- $\beta S$-Hoxa2-lacZ

口Col2a1/Hoxa2-lacZ 
Figure 2. Model featuring the molecular deregulation induced by Hoxa2 over-expression and associated with a proposed mechanism leading to idiopathic proportionate short stature. Molecular expressions are featured with their function and interactions on the left panel according to the mesenchymal (Colla1, upper quadrant), differentiating (Col2al, middle quadrant) and hypertrophic (Col10a1, lower quadrant) stages. Molecules are presented with their known interactions according to the literature [11,15,17,18,28,29,31-40]. Molecules that present a negative or positive influence on differentiation are shown in red and green, respectively (left panel). The factors that were reduced or increased in their protein levels in Col2a1/Hoxa2-lacZ are featured with red or green arrows, respectively (right panel). The stars indicate a significant difference observed using western blotting semi-quantification.

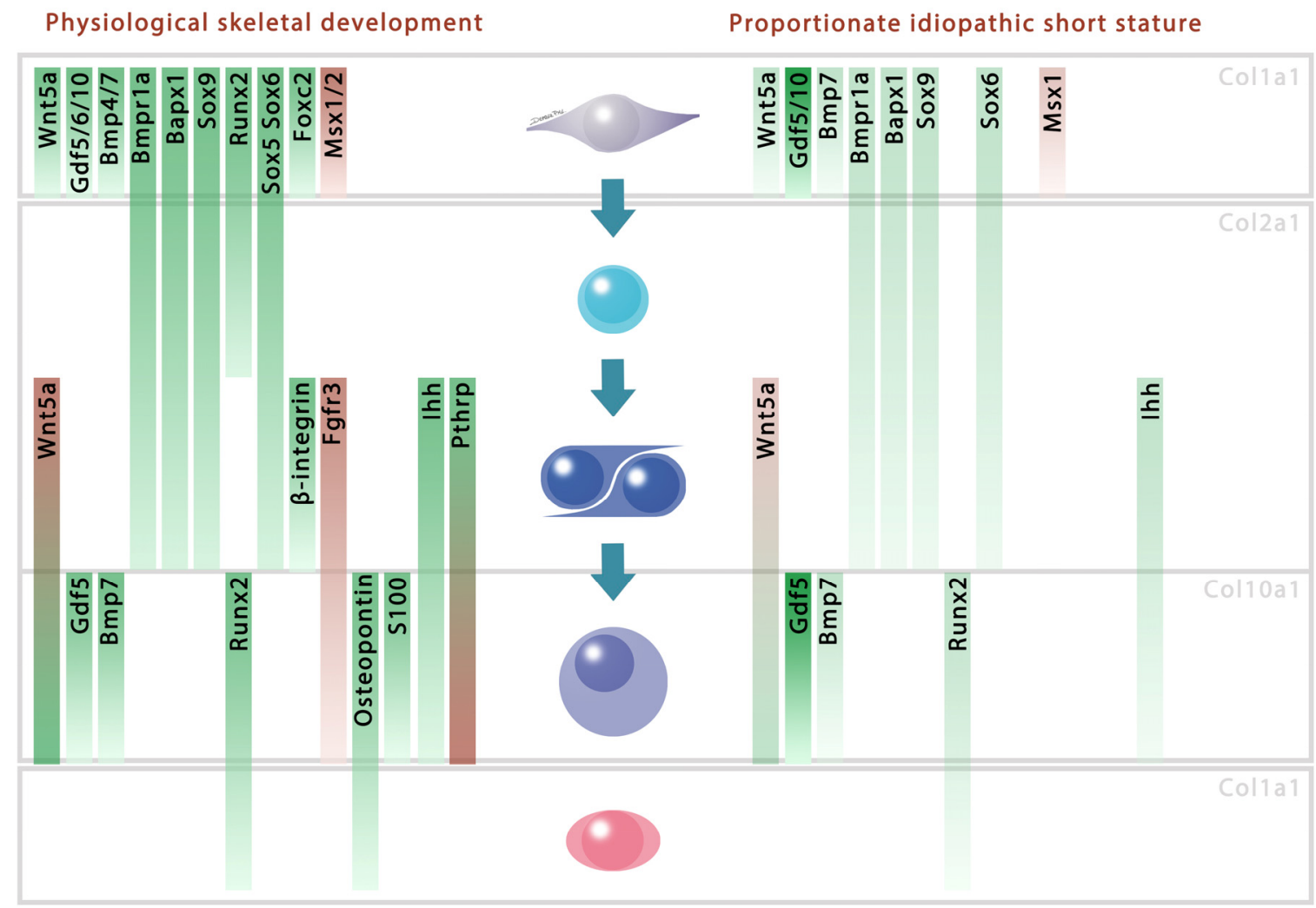

In conjunction with and as a possible consequence of this differentiation alteration, Ihh and Runx2, which stimulate the maturation of chondrocytes towards hypertrophy, showed a decrease in their protein levels (Figure 2). At this stage of the chondrogenic differentiation pathway, Bapx1 as well as Wnt5a were shown to stimulate $I h h$, characterizing the prehypertrophic stage of the chondrocytes [18,28]. Similarly, Bmp7 is known to induce hypertrophy through Runx2 stimulation [32]. The reduced protein levels of Bapx1, Wnt5a and Bmp7 may have resulted in a lower stimulation of Ihh and Runx2, leading to the observed lower protein accumulation and thereby explaining the decreased efficiency of the late maturation phase in endochondral ossification.

This Hoxa2 interference with both chondrogenic differentiation and the endochondral ossification cascade appears to be associated with a harmonious and proportionate short stature phenotype. On the other hand, the perturbation of either the proliferation or the hypertrophic stage by precise targeting of 
one or a combination of selected genes induces the formation of shorter but malformed skeletal elements. Wnt $5 a$ overexpressing mice, for example, feature a delay of chondrocyte hypertrophy and subsequent ossification, leading to a smaller but thicker appendicular skeleton [18]. In contrast, a regular hypertrophic development associated with a perturbed proliferation stage in PthrP knockouts induced a huge decrease in the proliferative column length and a slower cellular differentiation, leading to disproportionately short limbs with a correctly sized axial skeleton [41,42]. Bmp7 knockout mice featured a reduction in the length of both limbs and trunk. However, their phenotype was supplemented by other malformations like extra-digits or a fusion of the neural arch [27]. Runx2 deficient mice presented dwarfism but exhibited a deficit in calcification throughout the whole body, which is not the case for Col2a1/Hoxa2-lacZ [43]. When considering only the size reduction trait, $W n t 5 a$ knockouts exhibited a shorter but thicker skeleton $[18,44]$. Deficiencies in other actors were linked to a disproportionate short stature phenotype with a shortening of the trunk only in Bapx1 knockouts [26,45] or solely the limbs in Bmprla [19,46], Ihh [47] or Sox9 [48] loss-of-function. Pax9 [49] and Sox6 [50] deficient mice did not feature length reduction, despite the presence of an impressive phenotype when associated with a loss-of-function of their usual partners Paxl [51] or Sox5 [52]. These examples of inappropriate skeletal development were directly related to the deregulation of one factor and their skeletal phenotype was never related to PSS syndrome.

In contrast, the present phenotype resulting from Hoxa2 forced expression associates early differentiation disruption and proportionate short stature. Indeed, in the present mouse model, Hoxa2 is expressed as soon as mesenchymal cells differentiate into chondrocytes, i.e., concomitantly with Col2al expression, the marker of chondrogenesis initiation [3]. This failure is associated with a deregulation of protein levels whose combination induces a harmonious reduction of both the limbs and the vertebral column, a phenotype that is not observed upon individual chondrogenic gene misexpression. Although chondrogenesis is similar in the overall endochondral skeleton (i.e., every skeletal element except some parts of the skull and face, the mandible, the scapula and the lateral part of the clavicle [53-57]), an analysis of the chondrogenic actors in Col2a1/Hoxa2-lacZ limbs should be performed to confirm that the differentiation cascade is impaired in a similar way in all endochondral skeletal pieces, either during the embryonic period and during postnatal growth.

Other chondrogenic factors behaved differently in the Col2a1/Hoxa2-lacZ gain-of-function. Gdf and $M s x$ genes are also involved in the differentiation of mesenchymal cells into chondrocytes. Gdf5 and Gdf10 which positively control the differentiation of cells into chondrocytes in vivo and in vitro [58-60], are increased in Hoxa2 overexpressing mice (Figure 2). On the other hand, Msx1, which has a negative influence on early chondrogenesis [31], is decreased. Other factors that are involved in the endochondral ossification process, such as Bmp4 [33], Gdf6 [34] and PthrP [16] showed no protein level differences between control and mutant mice. These results are not necessarily contradictory with the negative influence of Hoxa2 over endochondral ossification given that a total loss of molecules involved in the chondrogenetic program would lead to a global deformity or absence of skeletal areas. Indeed, inactivation of $\operatorname{Sox} 9$ using $\operatorname{Prx} 1$-Cre transgene induced a complete loss of cartilage and bone in mice limbs [61]. Moreover, Runx2 null mice featured a total absence of calcified tissue leading to a boneless, cartilaginous skeleton except in the zeugopods [62].

Our data highlight a combined deregulation of distinct molecules under Hoxa2 overexpression, which is schematized in Figure 2. This selective deregulation is responsible for an impaired 
endochondral skeleton, as observed in E18.5 transgenics [3], and is associated with a postnatal proportionate short stature phenotype [4]. While the misregulation of the chondrogenic factors highlighted here globally and concurrently contribute to the phenotype, the triggering event(s) that are under the immediate influence of Hoxa2 need to be identified. In particular, further experiments must be performed to highlight Hoxa2 direct targets and to decrypt the unknown interactions between the chondrogenic factors. Therefore, although no clinical correlation has been reported so far between the deregulation of a Hox gene and the appearance of human PSS, a similar impingement during the transition of mesenchymal cells to chondrocyte and the resulting misregulation in the phases of endochondral ossification may be considered to be involved in proportionate short stature pathogenesis. Moreover, other Hox genes could be involved in such misregulation since it was demonstrated that severe cartilage defects in Hoxd4 and Hoxc8 overexpressing mice were related to chondrogenic molecules impairment [63,64]. Indeed, during their RT-PCR experiments, Kruger and Kappen showed that Mmps, Fgfs and even Ihh or Wnt5a were altered in their transgenics [64].

\section{Experimental Section}

\subsection{Transgenic Mice and Embryos}

Col2al-Cre [24] and hß-actin-lox-STOP-lox-Hoxa2-lacZ [3] transgenic mice were mated in order to obtain animals with both transgenes so that Hoxa2 expression was induced in Col2al expressing territories and maintained thereafter, i.e., throughout all of the endochondral elements of the skeleton. Animals carrying both transgenes are referred to as Col2al/Hoxa2-lacZ or mutant and mice bearing only the $h \beta$-actin-lox-STOP-lox-Hoxa2-lacZ transgene are referred to as $\beta S$-Hoxa2-lacZ or controls, for simplification purposes. Genotyping was performed by PCR, as described previously [4]. Experimental procedures were approved by the Animal Experimentation Ethics Committee of the Université catholique de Louvain (Ethical committee number 053001). Animal housing and handling were conducted according to the rules and regulations of the Belgian Federal State.

\subsection{Immunohistochemistry}

E13.5, E15.5 and E16.5 embryos $(n=5)$ were fixed in 4\% formaldehyde for at least $24 \mathrm{~h}$, embedded in paraffin and cut into $5 \mu \mathrm{m}$-thick sagittal slices. Sections were deparaffinized, rehydrated and were first treated for antigen retrieval with microwave exposure $(750 \mathrm{~W}$ for $3 \mathrm{~min}$ and 4 cycles of $350 \mathrm{~W}$ for $3 \mathrm{~min}, 30 \mathrm{~s}$ ) in a $0.01 \mathrm{M}$ citrate buffer solution [65] containing $0.17 \%$ tritonX-100. Some sections were subsequently treated with $20 \mu \mathrm{g} / \mathrm{mL}$ Proteinase K (Sigma-Aldrich, St. Louis, MO, USA) in distilled water at $37{ }^{\circ} \mathrm{C}$ for $5 \mathrm{~min}$ and then rinsed into $4{ }^{\circ} \mathrm{C}$ distilled water for $5 \mathrm{~min}$. Endogenous peroxidase was inhibited in all the tested sections using $1 \% \mathrm{H}_{2} \mathrm{O}_{2}$ during $20 \mathrm{~min}$ and unspecific staining was blocked with $3 \%$ normal goat serum for $30 \mathrm{~min}$. Samples were incubated overnight at room temperature with primary antibodies against Bapx1 (1:100), Runx2 (1:100), Sox5 (1:200), Sox6 (1:100), Bmprla (1:20), Foxc2 (1:10) (Abcam, Cambridge, UK), $\beta 1$-integrin (1:40), Bmp7 (1:25), Gdf10 (1:10), Gdf5 (1:100), Ihh (1:50), Wnt5a (1:30) (R \& D Systems, MS, USA), Bmp4 (1:50), Fgfr3 (1:100), Gdf6 (1:20), Meox1 (1:10), Meox2 (1:10), Pax1 (1:20), PthrP (1:100) (Santa Cruz Biotechnology Inc., Santa-Cruz, TX, USA), Msx1 (1:80) (Covance, NJ, USA), 
Msx2 (1:50) (United States Biological, Salem, MA, USA), Osteopontin (LF-124) (1:200) [66], Pax9 (1:100) (Genway, San Diego, CA, USA), S-100 (1:500) (ABR Affinity Bioreagents, Golden, CO, USA) and Sox9 (1:100) (Sigma-Aldrich, St. Louis, MO, USA). Thereafter, the sections were successively incubated with biotinylated Goat anti-rabbit, anti-mouse or Horse anti-goat secondary antibody (1:200) and treated with VECTASTAIN ABC Kit (Standard) (Vector laboratories, Burlingame, CA, USA) for $30 \mathrm{~min}$ each. Sections were stained with stable DAB (Life technologies,

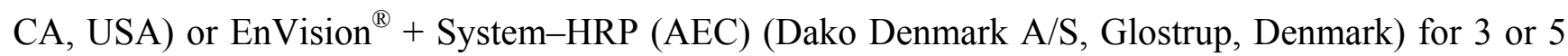
min respectively, and finally counterstained in Mayer's hematoxylin [67]. Unless mentioned, the sections were rinsed in 1\% PBS/BSA solution after each described step. For comparison, the most stained cervical vertebra in each section, i.e., the vertebra that featured the highest staining intensity and highest numberof stained chondrocytes, was photographed and considered for the experiment. Negative controls were obtained pre-incubating the antibodies with recombinant protein (according to manufacturer instructions). When unavailable, pictures were taken in an unstained area. Positive controls were verified on tissue specifically stained by the antibodies (Figure S1).

\subsection{Western Blotting}

Western blotting was performed as previously described [4]. Briefly, E13.5 $(n=5)$ total spines (from the first cervical to the last caudal vertebra) were dissected in PBS using sterile lancet and sonicated in $150 \mu \mathrm{L}$ Laemmli buffer containing complete protease inhibitor cocktail (Roche, Indianapolis, IN, USA) for $3 \times 30 \mathrm{~s}$ at frequency level 4 , spaced with a $30 \mathrm{~s}$ resting period on ice using Vibracell 75022 Ultrasonic processor (Bioblock scientific, Illkirch, France). The whole protein extract was estimated using BCA Protein Assay Reagent (Pierce Biotechnology Inc., Rockford, IL, USA). After incubation at $95{ }^{\circ} \mathrm{C}$ for $5 \mathrm{~min}, 30 \mu \mathrm{g}$ samples were loaded on gel electrophoresis and transferred to nitrocellulose membrane. After overnight blocking in PBS Tween $0.1 \%$ containing $5 \%$ powdered milk, membranes were incubated overnight with Bapx1 (1:5000), Runx2 (1:2500), Sox5 (1:10,000), Sox6 (1:10,000), Bmprla (1:25,000) (Abcam, Cambridge, UK), Bmp7 (1:10,000), Gdf10 (1:1000), Gdf5 (1:500), Ihh (1:30,000), Wnt5a (1:10,000) (R \& D Systems, Minneapolis, MN, USA), Bmp4 (1:10,000), Fgfr3 (1:5000), Gdf6 (1:100), PthrP (1:10,000) (Santa Cruz Biotechnology Inc., Santa-Cruz, TX, USA), Msx1 (1:10,000) (Covance, NJ, USA), Msx2 (1:10,000) (United States Biological, MA, USA), Pax9 (1:8000) (Genway, San Diego, CA, USA), $\beta$-actin (1:2000) and Sox9 $(1: 10,000)$ (Sigma-Aldrich, St. Louis, MO, USA) antibodies. After three washes in PBS Tween, membranes were incubated with biotinylated Goat anti-rabbit secondary antibody (1:200) and with VECTASTAIN ABC Kit (Standard) treatment (Vector laboratories, Burlingame, CA, USA) for 30 min each and were revealed using Pierce Supersignal West Pico trial kit (Pierce Biotechnology Inc., Rockford, IL, USA). The immunoblot band was processed for mean gray value measurement using Image J software (http://rsbweb.nih.gov/ij/index.html). Data normalization to measure the relative intensity of a given band was performed firstly after removal of the mean gray value of the background and then by reporting the measure obtained to that obtained for $\beta$-actin with the same sample. The data from $\beta$ S-Hoxa2-lacZ and Col2a1/Hoxa2-lacZ groups were compared with unpaired Student's $t$ test. All data are presented as mean value $(\mathrm{M}) \pm$ standard error of the mean (SEM). $p<0.05$ was assigned as significant difference. 


\section{Conclusions}

In conclusion, we propose a model that gives an insight into idiopathic proportionate short stature, displaying a decrease in proteins involved in the early phase of chondrocyte differentiation, i.e., the mesenchymal-to-chondrocyte step (Figure 2). This model involves a decrease in Bapx1, Bmp7, Bmpr1a, Ihh, Msx1, Pax9, Sox6, Sox9 and Wnt5a. Moreover, it is accompanied by a lowering of factors that are involved in the late differentiation phase of the endochondral ossification, i.e., Ihh and Runx2. The selective deregulation of these particular factors distributed along the chondrogenic pathway is likely to result in proportionate and harmonious, yet smaller skeletal growth.

\section{Acknowledgments}

The authors thank Doctor Larry W. Fisher from the Craniofacial and Skeletal Diseases Branch of the NIH (DHHS, Bethesda, Maryland) for kindly providing the Osteopontin antibody. We thank Heather Yates, Walter Hudders and Alicia Dessain for their skillful assistance. This work was supported by the Fonds Spéciaux de Recherche (FSR) of the Université catholique de Louvain (UCL). Miloud G. Nichane is Research Fellow from the Fonds de la Recherche Scientifique (FNRS, Belgium).

\section{Conflicts of Interest}

The authors declare no conflict of interest.

\section{References}

1. POSNA, Short Stature. Available online: http://www.posna.org/ (accessed on 3 February 2013).

2. Oostdijk, W.; Grote, F.K.; de Muinck Keizer-Schrama, S.M.; Wit, J.M. Diagnostic approach in children with short stature. Horm. Res. 2009, 72, 206-217.

3. Massip, L.; Ectors, F.; Deprez, P.; Maleki, M.; Behets, C.; Lengele, B.; Delahaut, P.; Picard, J.; Rezsohazy, R. Expression of Hoxa2 in cells entering chondrogenesis impairs overall cartilage development. Differentiation 2007, 75, 256-267.

4. Deprez, P.M.; Nichane, M.G.; Rousseaux, P.; Devogelaer, J.P.; Chappard, D.; Lengele, B.G.; Rezsohazy, R.; Nyssen-Behets, C. Postnatal growth defect in mice upon persistent Hoxa2 expression in the chondrogenic cell lineage. Differentiation 2012, 83, 158-167.

5. Baek, W.Y.; Kim, J.E. Transcriptional regulation of bone formation. Front. Biosci. 2011, 3, 126-135.

6. Marie, P.J. Transcription factors controlling osteoblastogenesis. Arch. Biochem. Biophys. 2008, 473, 98-105.

7. Eames, B.F.; de la Fuente, L.; Helms, J.A. Molecular ontogeny of the skeleton. Birth Defects Res. C Embryo Today 2003, 69, 93-101.

8. Cancedda, R.; Castagnola, P.; Cancedda, F.D.; Dozin, B.; Quarto, R. Developmental control of chondrogenesis and osteogenesis. Int. J. Dev. Biol. 2000, 44, 707-714.

9. Lefebvre, V.; Smits, P. Transcriptional control of chondrocyte fate and differentiation. Birth Defects Res. C Embryo Today 2005, 75, 200-212. 
10. Rodrigo, I.; Hill, R.E.; Balling, R.; Munsterberg, A.; Imai, K. Pax1 and Pax9 activate Bapx1 to induce chondrogenic differentiation in the sclerotome. Development 2003, 130, 473-482.

11. Church, V.; Nohno, T.; Linker, C.; Marcelle, C.; Francis-West, P. Wnt regulation of chondrocyte differentiation. J. Cell Sci. 2002, 115, 4809-4818.

12. Jiang, Y.Z.; Qi, Y.Y.; Zou, X.H.; Wang, L.L.; Ouyang, H.W. Comparison the effects of BMP-4 and BMP-7 on articular cartilage repair with bone marrow mesenchymal stem cells. IFMBE Proc. 2009, 23, 1285-1288.

13. Monsoro-Burq, A.H.; Bontoux, M.; Teillet, M.A.; le Douarin, N.M. Heterogeneity in the development of the vertebra. Proc. Natl. Acad. Sci. USA 1994, 91, 10435-10439.

14. Monsoro-Burq, A.H.; Duprez, D.; Watanabe, Y.; Bontoux, M.; Vincent, C.; Brickell, P.; le Douarin, N. The role of bone morphogenetic proteins in vertebral development. Development 1996, 122, 3607-3616.

15. Zeng, L.; Kempf, H.; Murtaugh, L.C.; Sato, M.E.; Lassar, A.B. Shh establishes an Nkx3.2/Sox9 autoregulatory loop that is maintained by BMP signals to induce somitic chondrogenesis. Genes Dev. 2002, 16, 1990-2005.

16. Minina, E.; Wenzel, H.M.; Kreschel, C.; Karp, S.; Gaffield, W.; McMahon, A.P.; Vortkamp, A. $\mathrm{BMP}$ and Ihh/PTHrP signaling interact to coordinate chondrocyte proliferation and differentiation. Development 2001, 128, 4523-4534.

17. Yoon, B.S.; Ovchinnikov, D.A.; Yoshii, I.; Mishina, Y.; Behringer, R.R.; Lyons, K.M. Bmprla and Bmprlb have overlapping functions and are essential for chondrogenesis in vivo. Proc. Natl. Acad. Sci. USA 2005, 102, 5062-5067.

18. Yang, Y.; Topol, L.; Lee, H.; Wu, J. Wnt5a and Wnt5b exhibit distinct activities in coordinating chondrocyte proliferation and differentiation. Development 2003, 130, 1003-1015.

19. Yoon, B.S.; Pogue, R.; Ovchinnikov, D.A.; Yoshii, I.; Mishina, Y.; Behringer, R.R.; Lyons, K.M. BMPs regulate multiple aspects of growth-plate chondrogenesis through opposing actions on FGF pathways. Development 2006, 133, 4667-4678.

20. Komori, T. Regulation of skeletal development by the Runx family of transcription factors. J. Cell Biochem. 2005, 95, 445-453.

21. Amano, K.; Ichida, F.; Sugita, A.; Hata, K.; Wada, M.; Takigawa, Y.; Nakanishi, M.; Kogo, M.; Nishimura, R.; Yoneda, T. MSX2 stimulates chondrocyte maturation by controlling Ihh expression. J. Biol. Chem. 2008, 283, 29513-29521.

22. Kempf, H.; Ionescu, A.; Udager, A.M.; Lassar, A.B. Prochondrogenic signals induce a competence for Runx2 to activate hypertrophic chondrocyte gene expression. Dev. Dyn. 2007, 236, 1954-1962.

23. Yamashita, S.; Andoh, M.; Ueno-Kudoh, H.; Sato, T.; Miyaki, S.; Asahara, H. Sox9 directly promotes Bapx1 gene expression to repress Runx2 in chondrocytes. Exp. Cell Res. 2009, 315, 2231-2240.

24. Ovchinnikov, D.A.; Deng, J.M.; Ogunrinu, G.; Behringer, R.R. Col2a1-directed expression of Cre recombinase in differentiating chondrocytes in transgenic mice. Genesis 2000, 26, 145-146.

25. Kanzler, B.; Kuschert, S.J.; Liu, Y.H.; Mallo, M. Hoxa-2 restricts the chondrogenic domain and inhibits bone formation during development of the branchial area. Development 1998, 125, 2587-2597. 
26. Lettice, L.A.; Purdie, L.A.; Carlson, G.J.; Kilanowski, F.; Dorin, J.; Hill, R.E. The mouse bagpipe gene controls development of axial skeleton, skull, and spleen. Proc. Natl. Acad. Sci. USA 1999, 96, 9695-9700.

27. Jena, N.; Martin-Seisdedos, C.; McCue, P.; Croce, C.M. BMP7 null mutation in mice: Developmental defects in skeleton, kidney, and eye. Exp. Cell Res. 1997, 230, 28-37.

28. Tribioli, C.; Lufkin, T. The murine Bapxl homeobox gene plays a critical role in embryonic development of the axial skeleton and spleen. Development 1999, 126, 5699-5711.

29. Yeh, L.C.; Mallein-Gerin, F.; Lee, J.C. Differential effects of osteogenic protein-1 (BMP-7) on gene expression of BMP and GDF family members during differentiation of the mouse MC615 chondrocyte cells. J. Cell Physiol. 2002, 191, 298-309.

30. Yoon, B.S.; Lyons, K.M. Multiple functions of BMPs in chondrogenesis. J. Cell Biochem. 2004, 93, 93-103.

31. Bendall, A.J.; Abate-Shen, C. Roles for Msx and Dlx homeoproteins in vertebrate development. Gene 2000, 247, 17-31.

32. Otto, F.; Lubbert, M.; Stock, M. Upstream and downstream targets of RUNX proteins. J. Cell Biochem. 2003, 89, 9-18.

33. Hatakeyama, Y.; Tuan, R.S.; Shum, L. Distinct functions of BMP4 and GDF5 in the regulation of chondrogenesis. J. Cell Biochem. 2004, 91, 1204-1217.

34. Shen, B.; Bhargav, D.; Wei, A.; Williams, L.A.; Tao, H.; Ma, D.D.; Diwan, A.D. BMP-13 emerges as a potential inhibitor of bone formation. Int. J. Biol. Sci. 2009, 5, 192-200.

35. Marsell, R.; Einhorn, T.A. The role of endogenous bone morphogenetic proteins in normal skeletal repair. Injury 2009, 40, S4-S7.

36. Meech, R.; Edelman, D.B.; Jones, F.S.; Makarenkova, H.P. The homeobox transcription factor Barx2 regulates chondrogenesis during limb development. Development 2005, 132, 2135-2146.

37. Kronenberg, H.M. Developmental regulation of the growth plate. Nature 2003, 423, 332-336.

38. Akiyama, H. Control of chondrogenesis by the transcription factor Sox9. Mod. Rheumatol. 2008, $18,213-219$.

39. Oh, C.D.; Maity, S.N.; Lu, J.F.; Zhang, J.; Liang, S.; Coustry, F.; de Crombrugghe, B.; Yasuda, H. Identification of SOX9 interaction sites in the genome of chondrocytes. PLoS One 2010, 5, e10113.

40. Bradley, E.W.; Drissi, M.H. WNT5A regulates chondrocyte differentiation through differential use of the CaN/NFAT and IKK/NF-kappaB pathways. Mol. Endocrinol. 2010, 24, 1581-1593.

41. Lanske, B.; Amling, M.; Neff, L.; Guiducci, J.; Baron, R.; Kronenberg, H.M. Ablation of the PTHrP gene or the PTH/PTHrP receptor gene leads to distinct abnormalities in bone development. J. Clin. Invest. 1999, 104, 399-407.

42. Karaplis, A.C.; Luz, A.; Glowacki, J.; Bronson, R.T.; Tybulewicz, V.L.; Kronenberg, H.M.; Mulligan, R.C. Lethal skeletal dysplasia from targeted disruption of the parathyroid hormone-related peptide gene. Genes Dev. 1994, 8, 277-289.

43. Ducy, P.; Starbuck, M.; Priemel, M.; Shen, J.; Pinero, G.; Geoffroy, V.; Amling, M.; Karsenty, G. A Cbfal-dependent genetic pathway controls bone formation beyond embryonic development. Genes Dev. 1999, 13, 1025-1036. 
44. Yamaguchi, T.P.; Bradley, A.; McMahon, A.P.; Jones, S. A Wnt5a pathway underlies outgrowth of multiple structures in the vertebrate embryo. Development 1999, 126, 1211-1223.

45. Akazawa, H.; Komuro, I.; Sugitani, Y.; Yazaki, Y.; Nagai, R.; Noda, T. Targeted disruption of the homeobox transcription factor Bapx1 results in lethal skeletal dysplasia with asplenia and gastroduodenal malformation. Genes Cells 2000, 5, 499-513.

46. Ovchinnikov, D.A.; Selever, J.; Wang, Y.; Chen, Y.T.; Mishina, Y.; Martin, J.F.; Behringer, R.R. BMP receptor type IA in limb bud mesenchyme regulates distal outgrowth and patterning. Dev. Biol. 2006, 295, 103-115.

47. St-Jacques, B.; Hammerschmidt, M.; McMahon, A.P. Indian hedgehog signaling regulates proliferation and differentiation of chondrocytes and is essential for bone formation. Genes Dev. 1999, 13, 2072-2086.

48. Akiyama, H.; Lyons, J.P.; Mori-Akiyama, Y.; Yang, X.; Zhang, R.; Zhang, Z.; Deng, J.M.; Taketo, M.M.; Nakamura, T.; Behringer, R.R.; et al. Interactions between Sox 9 and beta-catenin control chondrocyte differentiation. Genes Dev. 2004, 18, 1072-1087.

49. Peters, H.; Neubuser, A.; Kratochwil, K.; Balling, R. Pax9-deficient mice lack pharyngeal pouch derivatives and teeth and exhibit craniofacial and limb abnormalities. Genes Dev. 1998, 12, 2735-2747.

50. Smits, P.; Li, P.; Mandel, J.; Zhang, Z.; Deng, J.M.; Behringer, R.R.; de Crombrugghe, B.; Lefebvre, V. The transcription factors L-Sox 5 and Sox6 are essential for cartilage formation. Dev. Cell 2001, 1, 277-290.

51. Peters, H.; Wilm, B.; Sakai, N.; Imai, K.; Maas, R.; Balling, R. Pax1 and Pax9 synergistically regulate vertebral column development. Development 1999, 126, 5399-5408.

52. Smits, P.; Dy, P.; Mitra, S.; Lefebvre, V. Sox5 and Sox6 are needed to develop and maintain source, columnar, and hypertrophic chondrocytes in the cartilage growth plate. J. Cell Biol. 2004, 164, 747-758.

53. Abzhanov, A.; Rodda, S.J.; McMahon, A.P.; Tabin, C.J. Regulation of skeletogenic differentiation in cranial dermal bone. Development 2007, 134, 3133-3144.

54. Franz-Odendaal, T.A. Induction and patterning of intramembranous bone. Front. Biosci. 2012, 17, 3734-3746.

55. Hall, B.K. Development of the clavicles in birds and mammals. J. Exp. Zool. 2001, 289, 153-161.

56. Huang, L.F.; Fukai, N.; Selby, P.B.; Olsen, B.R.; Mundlos, S. Mouse clavicular development: Analysis of wild-type and cleidocranial dysplasia mutant mice. Dev. Dyn. 1997, 210, 33-40.

57. Kramer, J.; Klinger, M.; Kruse, C.; Faza, M.; Hargus, G.; Rohwedel, J. Ultrastructural analysis of mouse embryonic stem cell-derived chondrocytes. Anat. Embryol. 2005, 210, 175-185.

58. Buxton, P.; Edwards, C.; Archer, C.W.; Francis-West, P. Growth/differentiation factor-5 (GDF-5) and skeletal development. J. Bone Joint Surg. Am. 2001, 83, S23-S30.

59. Cho, T.J.; Gerstenfeld, L.C.; Einhorn, T.A. Differential temporal expression of members of the transforming growth factor beta superfamily during murine fracture healing. J. Bone Miner Res. 2002, 17, 513-520.

60. Dehne, T.; Schenk, R.; Perka, C.; Morawietz, L.; Pruss, A.; Sittinger, M.; Kaps, C.; Ringe, J. Gene expression profiling of primary human articular chondrocytes in high-density micromasses reveals patterns of recovery, maintenance, re- and dedifferentiation. Gene 2010, 462, 8-17. 
61. Akiyama, H.; Chaboissier, M.C.; Martin, J.F.; Schedl, A.; de Crombrugghe, B. The transcription factor Sox9 has essential roles in successive steps of the chondrocyte differentiation pathway and is required for expression of Sox5 and Sox6. Genes Dev. 2002, 16, 2813-2828.

62. Tu, X.; Joeng, K.S.; Long, F. Indian hedgehog requires additional effectors besides Runx 2 to induce osteoblast differentiation. Dev. Biol. 2012, 362, 76-82.

63. Yueh, Y.G.; Gardner, D.P.; Kappen, C. Evidence for regulation of cartilage differentiation by the homeobox gene Hoxc-8. Proc. Natl. Acad. Sci. USA 1998, 95, 9956-9961.

64. Kruger, C.; Kappen, C. Expression of cartilage developmental genes in Hoxc8- and Hoxd4-transgenic mice. PLoS One 2010, 5, e8978.

65. Gerard, A.C.; Many, M.C.; Daumerie, C.; Costagliola, S.; Miot, F.; DeVijlder, J.J.; Colin, I.M.; Denef, J.F. Structural changes in the angiofollicular units between active and hypofunctioning follicles align with differences in the epithelial expression of newly discovered proteins involved in iodine transport and organification. J. Clin. Endocrinol. Metab. 2002, 87, 1291-1299.

66. Fisher, L.W.; Stubbs, J.T., 3rd; Young, M.F. Antisera and cDNA probes to human and certain animal model bone matrix noncollagenous proteins. Acta Orthop. Scand. Suppl. 1995, 266, 61-65.

67. Bancroft, J.D.; Stevens, A. Theory and Practice of Histological Techniques, 4th ed.; Churchill Livingstone: Edinburgh, Scotland, 1996; p. 766.

(C) 2013 by the authors; licensee MDPI, Basel, Switzerland. This article is an open access article distributed under the terms and conditions of the Creative Commons Attribution license (http://creativecommons.org/licenses/by/3.0/). 